\title{
Evaluation of an Emergency Treatment Unit - in a Dis- trict General Hospital - Sri Lanka - A case Study
}

\author{
Himali R Wijegunasekara J L* \\ De Soyza Hospital for Women (Teaching), Srilanka
}

\begin{abstract}
Emergency Treatment Unit of a hospital is the place where, acutely unwell patients admitted to the hospital, are given the immediate treatment in the critical stage. DGH - Gampaha - Sri Lanka is a tertiary care hospital with a bed strength of 795 with a well - recognized Emergency Treatment Unit. Objective of this study was to evaluate the Emergency Treatment Unit of District General Hospital, Gampaha, Sri Lanka.

Data was collected through oobservations, key informant interviews and reviewing registers and records.

Findings were subjected to SWOT analysis.

1) Identified strengths included accessibility, Infrastructure, ETU concept, 24 hour service, competent staff, availability of equipment and investigation facilities and Information management.

2) Some weaknesses identified were; shortage of staff, absenteeism, gaps in competency, shortage of equipment and inadequate quality management system.

3) Receiving priority attention by the provincial, regional and the hospital management, Administration Support Team, Hospital Management Committee, Hospital Clinical Society, Hospital Development Committee, Hospital Development Foundation and regular donations were recognized as opportunities.

4) Finally, Unnecessary transfers from peripheral hospitals, by pass of peripheral hospitals by patients, frequently changing of the management and delay in procurement, repairing and condemning processes were noted as threats.

TOWS analysis using a TOWS matrix was performed and strategies were developed for further improvement.
\end{abstract}

Keywords: Hospital, Emergency treatment, Patients, SWOT

\section{Introduction}

\section{Emergency treatment unit}

Emergency treatment unit of a hospital is the place where, acutely unwell patients admitted to the hospital, are given the immediate treatment in the critical stage. The survival rate of the patients are largely depend on the quality and efficiency of the services provided by ETUs. ETUs are expected to cope with increased amount of patients while securing delivery of high quality and effi- ciency. This target can be achieved by promotion of interdisciplinary teamwork, timely and high-quality treatment, early diagnosis and effective treatment of patients with comorbidities.

\section{District General Hospital (DGH) gampaha}

District General Hospital (DGH) gampaha is a tertiary care hospital in the western province of Sri Lanka with a bed strength of 795; total admission per day of 286; bed occupancy rate of $70 \%$; average length of stay of 2.33 days; and average daily census being

\begin{tabular}{|l|l|}
\hline \hline Quick Response Code: & *Corresponding author: Himali R Wijegunasekara JL, Deputy Director, De Soyza Hospital for \\
Women (Teaching), Colombo, Sri Lanka \\
Received: 25 August, 2021 \\
Citation: Himali R Wijegunasekara JL. Evaluation of an Emergency Treatment Unit - in a Dis- \\
trict General Hospital - Sri Lanka - A case Study. SOJ Med Clin Case Rep. 2021;1(1):1-4. D0I: \\
$10.53902 / S O J M C C R .2021 .01 .000505$
\end{tabular}


558. Emergency treatment is provided to acutely unwell patients, in the Preliminary Care Unit (PCU) established in the ground floor of the front most building complex.

\section{Objective}

To evaluate the Emergency Treatment Unit (ETU) of District General Hospital, Gampaha, Sri Lanka.

\section{Data Collection}

Data collection was done by Observation, Key informant Interviews with the In - charge Nursing Officer, In - Charge Medical Officer, Director, Matron and the Medical Officer - Quality Management Unit and reviewing registers and records.

\section{Findings}

In this DGH, emergency treatment is provided to acutely unwell patients, in the Preliminary Care Unit (PCU) situated next to the reception counter in the main building. PCU functions for 24 hours. Patients attended between 8 am - 8 pm, are admitted by the Outpatient (OPD) admission officer and those attended between 8 pm -8 am, are directly admitted by the PCU.

There is a well spacious, modern PCU especially constructed according to correct layout of a PCU. There is a triage area with a doctor, admission table, areas for pediatrics, emergency medicine, emergency surgery, surgical dressing, observation, nurses' station, doctors' station, drugs and equipment rooms, office rooms and rest rooms.

It has been started in 2002 as one of the first PCUs in Sri Lanka. Since then patient load is gradually increasing. At present, 200-250 patients receive the service from PCU per day out of which 70-80 patients come at night. There is a diurnal variation with morning hours from $8 \mathrm{am}-12 \mathrm{pm}$ having the height number.

Staff consists of 24 doctors, 21 nurses, 3 attendants and 7 laborers. All the categories work in shifts. Number allocated are done proportionate to the patient load. About $40 \%$ of patients admitted are discharged after treatment at PCU reducing the burden to wards. Rest is transferred to relevant wards, Medical Intensive Care Unit (MICU), Surgical Intensive Care Unit (SICU), Neonatal Intensive Care (NICU), Coronary Care Unit (CCU) or infrequently to National Hospital of Sri Lanka (NHSL). Average of 5-6 patients per day leave against medical advice and there are about 4 patients missing per day. It receives about 15 transfers from peripheral hospitals a day. According to midnight report average of 15 patients are given care at midnight. Average death rate is $0.5 \%$ per day.

Additionally, investigations such as ECG, X-ray and blood tests are done in relevant departments situated in the first floor of the same building. There are 2-3 doctors and 5 nurses work at night.
Minor staff is allocated to transport patients to wards, CCU, MICU, to send patients to $\mathrm{x}$-rays, to carry lab samples, to bring back reports, to send referrals to medical, surgical and pediatrics wards and so on.

\section{SWOT Analysis}

\section{Strengths}

a) It is situated in the front most place with easy accessibility from main entrance; having a spacious triage area with a 24-hour 4 triage nurses and 4 minor staff; having an adequate space and proper layout; practicing ETU concept with 2 acute side beds; displaying - triage score at the entrance for reference.

b) It is equipped with 23 beds, 1 trolley and 19-wheel chairs; one multi- para-monitor, 3 laryngoscopes, 4 pulse oxy-meters, adequate ET tubes, fridges, crash carts and cupboards, having wall oxygen and drugs including streptokinase.

c) It receives the service of 4 operating theatres in the $7^{\text {th }}$ flow of the same building with lift facilities, ECG, X-ray and laboratory facilities for FBC, UFR and RBS in the first floor of the same building, consultants such as VP OPD, Pediatrician and Surgeon visiting daily and on on-call days. It has got all the essential drugs required.

d) Corporation of the MOIC is satisfactory; In-charge nurse is having 3 years experience and committed to work; Staff has participated in different training such as ETU management, dengue management, disaster management, CPR and wound care.

e) PCU is prepared for a disaster with a separate cupboard with necessary equipment and medicine. There is a disaster management plan to the hospital. A disaster drill has been done 1 year ago.

f) Health related information is collected as daily statistics. In addition, data regarding trauma are collected.

\section{Weaknesses}

a) There is no sister in-charge. There is a shortage of nurses and minor staff. There is a bad absenteeism and poor attitudes among minor staff which has affected to fast work in the PCU. No proper training has been given to staff particularly to the minor staff. CPR competency is not adequate. Staff becomes panic when doing critical care procedures. Incharge nurse is demotivated.

b) There is a severe shortage of multi monitors. There are broken laryngoscopes and oxygen regulators which need 
repairing or condemning. Minor staff has not been trained for proper operation of oxygen regulators. There is no dengue scan to exclude acute phase of dengue. No Troponin T / or dengue antibodies are done. Bed space is not adequate. There are only 2 beds for acute care.

c) Quality improvement teams (WIT) are not functioning after 2014. No mortality reviews are done. No incidence reporting/medical errors reporting or reporting of re admissions. No patient satisfaction surveys or employer satisfaction surveys has been done. No suggestion box/complain box available. A\&E Concepts such as red/yellow/green is not practicing now.

\section{Opportunities}

a) DGH Gampaha is the largest hospital in Gampaha district receiving the greatest attention of the ministry and the Provincial and regional directorates. There is a motivated, co-operative and a visionary director appointed recently to the hospital. In-charge meeting is conducted every month. There is a well -functioning hospital development committee and a hospital development foundation which has offered 25000/ month for emergency drugs and glucose strips etc. for 10 years. There is a quality improvement unit with committed staff. There is good inter - sectoral collaboration between the hospital and other agencies. Hospital gets frequent donations from donors.

b) Hospital clinical society meeting is conducted with some satisfaction and the doctors' participation is satisfactory. There is an administrative supportive team with voluntary participation composed of the deputy director, matron, MOIC, VP OPD, Pathologist and the Psychiatrist.

c) There are male nurses with OT, SICU and PCU experience doing night duty with over time cover. Nurses are provided from wards for transport of patients to other hospitals.

d) There are Operation Theatres, Laboratory and ECG and X-ray departments in the same building.

\section{Threats}

a) Director/Matron/ AO/ Over-sear and accountant have not taken PCU as section which should be treated as a priority. b) Directors have been frequently changed.

c) With the popularity of the hospital, patient load has increased by - passing peripheral hospitals.

d) It has over- burdened the PCU. There are delays in processes of procurement, repairs and condemning.

e) No in-service training is organized by the higher authorities.

f) Bio medical unit is situated outside the hospital premises. ${ }^{1-3}$

Table 1

\section{Recommendations}

a) Work Improvement teams are to be functional for better productivity

b) Conduct Quality/Safety reviews to identify gaps for correction

c) Health Information Management to be further strengthened

d) Improve patient satisfaction

e) Improve staff satisfaction

f) Improve efficiency of the staff

g) Improve competency of the Staff

h) Provide adequate equipment / facilities

i) Improve Quality and safety of patient care

j) Establish a shared care cluster system

k) Strengthen management competencies of the staff

I) Establish criteria for the admission and transfer mechanism

m) Out Sourcing supportive services

n) Private Public partnership

\section{Acknowledgments}

None.

\section{Funding}

None.

\section{Conflicts of Interest}

Author declares that there is no conflict of interest. 
Table 1: TOWS matrix was used for the analysis and to develop strategies for implementations.

\begin{tabular}{|c|c|c|}
\hline \multirow{11}{*}{$\begin{array}{l}\text { External } \\
\text { Factors }\end{array}$} & Strengths & Weaknesses \\
\hline & S1 Easy Accessibility & W1 Shortage of MOs and Nos \\
\hline & S2 Good Infrastructure & W2 Bad absenteeism of SKS \\
\hline & S3 24 hour service provision & W3 No Sister In Charge \\
\hline & S4 ETU concept is followed & W4 Gaps in CRP competency \\
\hline & S5 Trained \& committed staff & W5 Shortage of Multi monitors \\
\hline & S6 Visiting consultants & W6 Some tests are not done \\
\hline & S7 Fully equipped ETU & W7 Only 2 beds in acute side \\
\hline & S8 Lab/OT/X ray Facilities & W8 Dysfunctional WITs \\
\hline & S9 All the essential drugs & W9 No Performance Reviews \\
\hline & S10 Information management & W10 Gaps in data collection \\
\hline Opportunities & SO Strategies & WO Strategies \\
\hline 01 Attention of MoH/ PD/RD & \multirow{2}{*}{$\begin{array}{l}\mathrm{S} 5, \mathrm{~S} 6, \mathrm{~S} 10,02,04-\text { Work Improvement teams } \\
\text { are to be functional for better productivity }\end{array}$} & \multirow{2}{*}{$\begin{array}{c}\text { W1,W2,W3,W9,02,03,04,09 -Improve efficiency } \\
\text { of the staff }\end{array}$} \\
\hline O2 Motivated, visionary MS & & \\
\hline O3 Administration Support Team & \multirow{3}{*}{$\begin{array}{l}\text { S4, S5, S10, 01,02,04, } 09 \text {-Conduct Quality/ } \\
\text { Safety reviews to identify gaps for correction }\end{array}$} & \multirow{3}{*}{$\begin{array}{c}\text { W1, W2,W3,W4,W9,01,04,09 - Improve compe- } \\
\text { tency of the Staff }\end{array}$} \\
\hline 04 Hospital Quality Improvement Unit & & \\
\hline O5 Hospital Management Committee & & \\
\hline O7 Hospital Dev. Foundation & $\begin{array}{l}\text { S3,S5,S10,02,04 - Health Information Man- } \\
\text { agement to be further strengthened }\end{array}$ & $\begin{array}{c}\text { W5,W6, W7, 01,06,07,08 -Provide adequate } \\
\text { equipment / facilities }\end{array}$ \\
\hline 08 25000/- donation/month & $\begin{array}{c}\mathrm{S} 1, \mathrm{~S} 2, \mathrm{~S} 3, \mathrm{~S} 5, \mathrm{~S} 6, \mathrm{~S} 7, \mathrm{~S} 8, \quad 02,010 \text {-Improve pa- } \\
\text { tient satisfaction }\end{array}$ & \multirow{3}{*}{$\begin{array}{c}\text { W4,W6,W9,W10, 04,05,09 - Improve Quality and } \\
\text { safety of patient care }\end{array}$} \\
\hline 09 Clinical Society Meeting & \multirow{2}{*}{$\begin{array}{c}\mathrm{S} 1, \mathrm{~S} 5, \mathrm{~S} 6,02,03,04,09,08 \text { - Improve staff } \\
\text { satisfaction }\end{array}$} & \\
\hline 010 Staff sent from other units & & \\
\hline Threats & ST Strategies & WT Strategies \\
\hline $\begin{array}{l}\text { T1 Peripheral hospitals are not devel- } \\
\text { oped }\end{array}$ & \multirow{4}{*}{$\begin{array}{c}\text { S3,S6,S7,S8,T1,T2 - Establish a shared care } \\
\text { cluster system }\end{array}$} & \multirow{3}{*}{$\begin{array}{c}\text { W1,W5,W6,W7, T1,T2 Establish criteria for the } \\
\text { admission and transfer mechanism }\end{array}$} \\
\hline T2 Unnecessary transfers & & \\
\hline T3 Frequently changing of MSs & & \\
\hline T4 Less priority from management & & \multirow{2}{*}{ W2,T5, T6,T7 - Out Sourcing supportive services } \\
\hline T5 Delay in procurement of items & \multirow{4}{*}{$\begin{array}{l}\text { S5, S6, T3,T4,T5,T7,T8,T9 - Strengthen man- } \\
\text { agement competencies of the staff }\end{array}$} & \\
\hline $\begin{array}{l}\text { T6 Bio Medical Unit lies outside the hos- } \\
\text { pital }\end{array}$ & & \multirow{3}{*}{ W5,W6,W7,T5, T7, T8 - Private Public partnership } \\
\hline T7 Delay in repairing equipment & & \\
\hline T8 Delay in condemning of items & & \\
\hline
\end{tabular}

\section{References}

1. Accident and Emergency Care Policy of Sri Lanka. Ministry of Health, Nutrition and Indigenous Medicine; 2015.

2. Guidelines for Accident and Emergency Care Services in Government Hospitals in Sri Lanka; Ministry of Health, Nutrition \& Indigenous Medicine Sri Lanka; 2016.
3. O'Reilly GM, Fitzgerald MC, Ariyananda PLS, et al. Delivering emergency and trauma care in Sri Lanka in 2017 - A decade of change and leadership by the Emergency Treatment Unit of Teaching Hospital Karapitiya"; Journal of the Ceylon College of Physicians. 2017;48:15-19. 